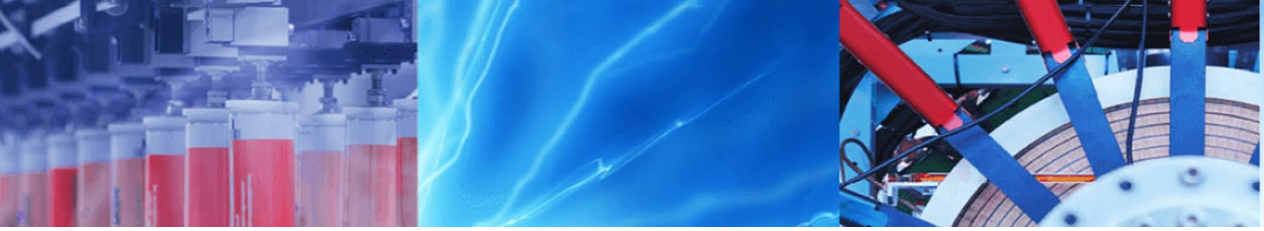

Research Article

\title{
Design of voltage and current controller parameters using small signal model-based pole-zero cancellation method for improved transient response in microgrids
}

\author{
Y. V. Pavan Kumar ${ }^{1}$ (D) - Ravikumar Bhimasingu ${ }^{2}$ (D)
}

Received: 12 May 2020 / Accepted: 8 September 2021

Published online: 09 October 2021

(C) The Author(s) 2021 OPEN

\begin{abstract}
Microgrids are supposed to provide stable power for seamless utility-grid interaction under all conditions as stated by IEEE-1547 standard. But, the use of power electronic inverter makes the microgrid sensitive to transients than synchronous generator-based plants. This degrades the voltage/frequency responses during transients, which can lead to transient stability problem if not controlled properly. Hence, the design of effective closed-loop voltage and current (V/I) controllers is highly desired to control the inverter output against the disturbances. The V/I controllers are based on PI (proportional-cum-integral) formulas. Thus, the effectiveness of $\mathrm{V} / \mathrm{I}$ controllers relies on how accurate that their gain parameters are tuned. Many PI-tuning methods have been developed in the literature, but, it is yet difficult to identify a suitable method for an application. Also, only a few researchers have focused on the microgrids due to the complexity involved in its controller design by the presence of $\mathrm{V} / \mathrm{I}$ cascaded dual-loop. Hence, to address this problem, this paper proposes a novel way of designing V/I controller parameters by using pole-zero cancellation method. This method is implemented by deriving the microgrid's small-signal model. This improves the transient response through reduced system order and/or alleviated sluggish/marginal-stable/unstable poles by adding zeros at same places where those poles are laid, to in effect cancel them. The efficacy of the proposed method over existing methods is assessed by plotting frequency and voltage responses under different test conditions. From the simulation results, it is witnessed that the proposed method relatively improved the transient characteristics of microgrids.
\end{abstract}

\section{Article Highlights}

- Analyzes the applicability of conventional PI tuning methods for microgrid controllers' design.

- Proposes a novel small signal model based pole-zero cancellation method for the design of microgrid controllers.
- Enhances the gain margin, which improves the stabilization capacity of the system when subjected to disturbances.

- Improves the transient behavior of frequency and voltage responses, which ensure the safety of sensitive loads.

Keywords Microgrids · Voltage controller $\cdot$ Current controller $\cdot$ PI tuning $\cdot$ Small-signal model $\cdot$ Transient response

$\triangle$ Y.V. Pavan Kumar, pavankumar.yv@vitap.ac.in | 'School of Electronics Engineering, VIT-AP University, Amaravati 522237, Andhra Pradesh, India. ${ }^{2}$ Department of Electrical Engineering, Indian Institute of Technology Hyderabad (IITH), Hyderabad 502285, Telangana, India.

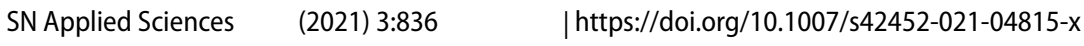




\section{Nomenclature}

$\begin{array}{ll}\text { Acronyms } & \\ \text { CLTF } & \text { Closed-loop transfer function } \\ \text { EPI } & \text { Error Performance Index } \\ \text { MG } & \text { Microgrid } \\ \text { MPZC } & \text { Small signal model based pole-zero } \\ & \text { cancellation } \\ \text { OLTR } & \text { Open-loop transient response } \\ \text { OLTF } & \text { Open-loop transfer function } \\ \text { PEVSI } & \text { Power electronic voltage source inverter } \\ \text { PIC } & \text { Proportional-integral controller } \\ \text { PWM } & \text { Pulse width modulation } \\ \text { PZC } & \text { Pole-zero cancellation } \\ \text { RESM } & \text { Renewable energy sourced microgrid } \\ \text { THD } & \text { Total harmonic distortion } \\ \text { UG } & \text { Utility-grid } \\ \text { V/I } & \text { Voltage and current }\end{array}$

Variables and Parameters

\section{Three-Phase Parameters}

$\begin{array}{ll}R_{f}^{a b c}, L_{f}^{a b c} & \begin{array}{l}\text { Series resistance }(\Omega) \text {, Series inductance }(\mathrm{mH}) \\ \text { of filter }\end{array} \\ C_{f}^{a b c}, G_{f}^{a b c} & \begin{array}{l}\text { Shunt capacitance }(\mu \mathrm{F}), \text { conductance }(\mathrm{J}) \text { of } \\ \text { filter }\end{array} \\ R_{g}^{a b c}, L_{g}^{a b c} & \text { Line resistance }(\Omega), \text { Line inductance }(\mathrm{mH}) \text { of } \\ & \text { grid } \\ V_{o}^{a b c}, I_{o}^{a b c} & \text { Load bus measurements - voltage }(\mathrm{V}), \text { cur- } \\ & \text { rent }(\mathrm{A}) \\ V_{p w m}^{r e f} & \text { Reference input }(\mathrm{V}) \text { given to PWM generator } \\ V_{s}^{a b c} & \text { Inverter output voltage }(\mathrm{V}) \\ V_{i}^{a b c} & \text { Series branch voltage }(\mathrm{V}) \text { of the filter } \\ l_{i}^{a b c} & \text { Current }(\mathrm{A}) \text { drawn from the Inverter } \\ V_{g}^{a b c} & \text { Utility-grid voltage }(\mathrm{V}) \\ l_{c}^{a b c} & \text { Current }(\mathrm{A}) \text { flowing in shunt branch of Filter }\end{array}$

\section{$d q$ Parameters}

$V_{o}^{d q} \quad V_{d o}, V_{q o}=d q$ Equivalents of $V_{o}^{a b c}(\mathrm{~V})$

$I_{o}^{d q} \quad I_{q o}, I_{d o}=q d$ Equivalents of $I_{o}^{a b c}(\mathrm{~A})$

$V_{d o}^{r e f}, V_{q o}^{r e f} \quad$ Reference inputs given to voltage controller

(V)

$I_{d i}^{r e f}, I_{q i}^{r e f} \quad$ Reference current inputs of current controller

(A)

$e_{d,} e_{q}$
$l_{i}^{d q}$
$l_{i}^{r e f}$
$V_{o}^{r e f}$

dq Components of $V_{p w m}^{r e f}(\mathrm{~V})$

$I_{q i}, I_{d i}=q d$ Components of $l_{i}^{a b c}(\mathrm{~A})$

$I_{d i}^{r e f}$ or $I_{q i}^{\text {ref }}=$ Reference current for $l_{i} \operatorname{control}(\mathrm{A})$

$V_{d o}^{r e f}$ or $V_{q o}^{r e f}=$ Reference voltage for $V_{o}$ control

(V)

\section{Single-Phase Parameters}

$R_{f} L_{f}$

$C_{f}, G_{f}$

$R_{g^{\prime}} L_{g}$

$V_{s}, V_{i}, V_{o}$

$I_{i}, I_{c}, I_{O}$

Single phase representation of $R_{f}^{a b c}, L_{f}^{a b c}$

Single phase representation of $C_{f}^{a b c}, G_{f}^{a b c}$

Single phase equivalent of $R_{g}^{a b c}, L_{g}^{a b c}$

Single phase equivalent of $V_{s}^{a b c}, V_{i}^{a b c}, V_{o}^{a b c}$

Single phase equivalent of $I_{i}^{a b c}, l_{c}^{a b c}, l_{0} a_{0}{ }^{o}$

\section{Other Parameters}

$V_{d c}^{m g}, V_{a c}^{m g} \quad$ Microgrid's DC, AC bus voltages respectively (V)

$\begin{array}{ll}\omega & \text { Angular frequency (rad/sec) } \\ K_{P V}, K_{I V} & \text { PIC components of voltage controller } \\ K_{P A}, K_{I A} & \text { PIC components of current controller }\end{array}$

\section{Introduction}

The modern power system is facing profound changes by the integration of more and more renewable energy sourced microgrid (RESM) plants to the utility-grid to get rid of issues with conventional fossil fuel-based energy. However, the fruitful operation of RESMs is majorly affected by the intermittent renewable energy availability and dependency on harmonic prone power electronic voltage source inverter (PEVSI). Further, as a generalpurpose utility grade plant, the RESM needs to be operated under typical industrial/residential load conditions that have a wider degree of variability. These variabilities mainly include imbalances in the load-bus voltage or utility-grid voltage due to single-phase distribution systems, nonlinear load actions, momentary faults, disturbances, etc. Compared to synchronous generator-based power plants, PEVSI-based RESMs possess negligible inertia and kinetic energy. So, RESMs are considered sensitive, which produce degraded voltage and frequency response during the variabilities mentioned above [1-3]. These degraded responses can further lead to transient stability problem if not controlled appropriately. To address the abovementioned issues, the state-of-the-art solutions suggest, optimal use of storage devices to handle the irregularity in renewable energy availability [4-6], refined multilevel or modular PEVSI configurations with reduced complications (e.g., fault tolerant operations during switch failures, use of less number of circuit components, etc.) to handle harmonic distortion issues [7-9], and the development of different voltage and current (V/I) control methods [10-12] and droop control methods [13-15] to handle power quality and power sharing issues, respectively. All these 
solutions help to improve the RESM's steady-state stability, but, the concerns of oscillatory responses during smallsignal disturbances are yet predominant. These transient response issues rely on the timely response and fidelity of the PEVSI's controller, i.e., the V/I controllers.

In each closed-loop control cycle, the $\mathrm{V} / \mathrm{I}$ controllers produce the control (or reference/modulation) signal to the PWM generator as given in Fig. 1 by controlling the load variations and disturbances occurred at the load-bus. Based on this control signal, the PWM generator produces the necessary firing pulses to regulate the PEVSI output. The V/I controllers are the proportional-integral controller (PIC)-based algorithms. Therefore, the desired operation of $\mathrm{V} / \mathrm{I}$ controllers to address the transient response issues depend on the accurate design of its PIC gain parameters.

To design gain parameters of PICs used in different applications, there are several tuning methods have been continuously evolving as discussed in [16-24]. Apart from these conventional methods, pole-zero cancellation (PZC) method is being used to design PICs in different applications such as, design of pulse pile-up tracking system used in amplifiers to generate lower noises [25], design of harmonic controller for a STATCOM [26], in multistage amplifiers to decrease the size of compensation capacitor, output power transistor, and to increase the power-bandwidth efficiency [27], for reducing the forced vibration in an end milling process application [28], for high speed sample and hold circuit design used in pipeline analog-digital converters [29], design of CdTe diode-based radiation detectors [30], design of gain scheduling control method for DC/ DC converter [31], design of low noise power amplifier used in UWB systems [32], for increasing the phase and gain margin in feedback systems [33], design of current controller for electric machines [34], design of 3-phase synchronous reference frame PLLs [35], design of levitated object position controller for magnetic levitation systems [36], in CMOS transconductance operational amplifiers with the help of settling time computations [37], to expand the bandwidth of dual-mass MEMS gyroscopes [38], in first-order and time-delay systems for rate limiting of actuators [39], etc.

The concept of PZC method is to compensate the unstable poles (open-loop right-half-plane poles) or sluggish/marginal stable poles (poles at or nearby origin) by adding zeros at the same locations where those undesired poles are laid, to in effect compensates the effect of those poles. Despite using the PZC method effectively in controller design for many applications, while, to the best of authors' knowledge based on the above-reported literature, it has never been used to design the V/I controllers of RESMs. Hence, the applicability of PZC method for the design of dual-loop V/I controllers for RESMs is worthy of serious consideration. With this objective, this paper proposes the "Small Signal Model Based Pole-Zero Cancellation (MPZC) method" to design the PIC parameters of $\mathrm{V} / \mathrm{I}$ controllers used in RESMs. The contributions of this paper are outlined as follows.

- Analyzing the applicability of conventional PIC tuning methods discussed in [16-24] for the design of RESM's controller. A quantitative analysis is presented in Sect. 5.1. This analysis further helps to identify the best conventional method to compare with the proposed method to persuade the importance of the proposed method.

- Design of the proposed MPZC methodology for the design of $\mathrm{V} / \mathrm{I}$ controller gains to achieve the improved

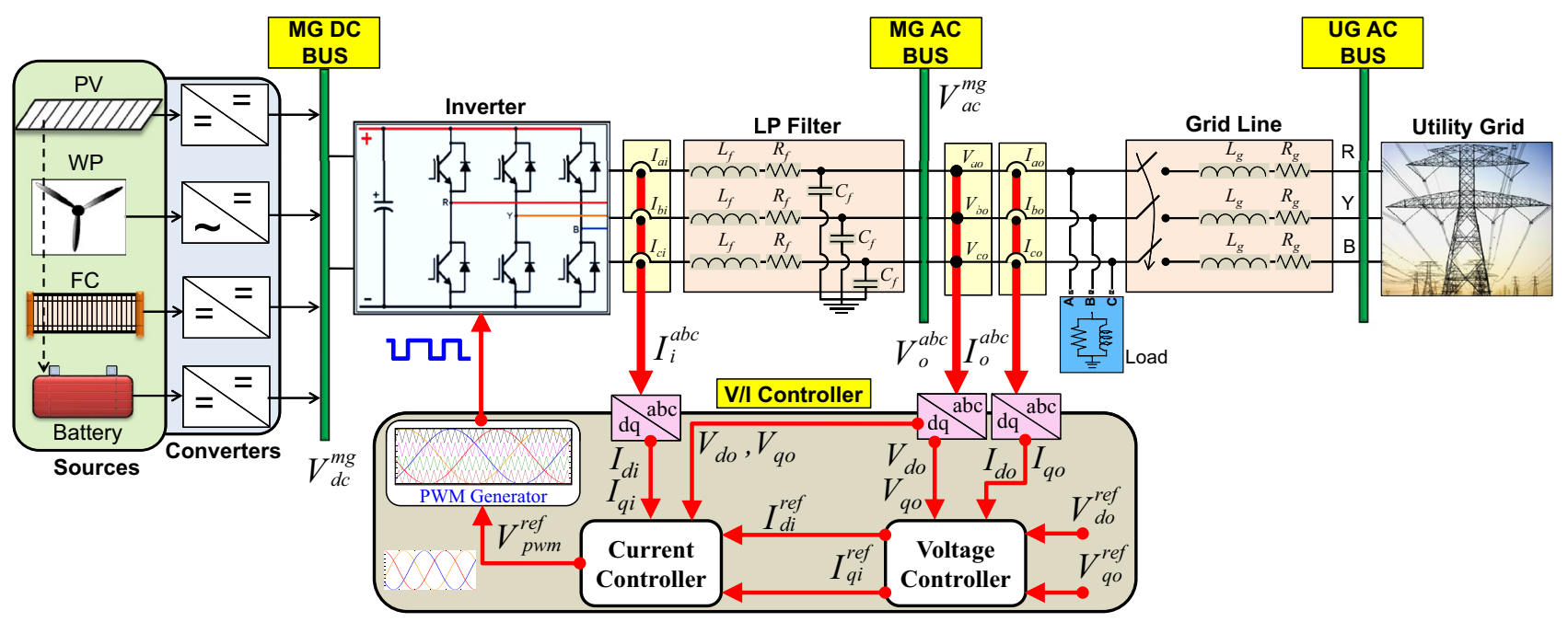

Fig. 1 Representation of the renewable energy sourced microgrid (RESM) plant 
transient response in RESMs over the conventional methods.

- Conducting adequate simulation analysis with different test conditions to judge the usefulness of the proposed method compared to the conventional methods.

The other sections of the paper are arranged as follows. Section 2 describes the V/I controller operation in RESMs. Section 3 describes the development of proposed small signal model of the RESM. Section 4 describes the development of conventional and proposed methods for designing the $\mathrm{PIC}$ parameters used in V/I controllers. Section 5 presents the comparative results, which also includes the analysis on the applicability of conventional tuning methods for the design of RESM's V/I controller. To conclude, Sect. 6 provides the cumulative remarks and achievements of this paper.

\section{Description of the $\mathrm{V} / \mathrm{I}$ controller operation}

The RESM schematic shown in Fig. 1 is an integrated entity of renewable sources with associated converters, storage units, PEVSI, V/I controllers, load, and utility-grid connection. The V/I controller works in a closed-loop between the AC (or load) bus and the PEVSI. This is formed with the cascaded connection of voltage and current controllers given in Fig. 2a and Fig. 2b [3]. The corresponding operational relations of V/I controller are given as (1)-(6), which produces the threephase reference signal to PWM generator as referred in (7), using the inverse park transformation formula. Based on this reference (or modulation) signal, the PWM generator produces the switching signals to control the PEVSI's switches, which subsequently controls its output.

$$
\begin{aligned}
& I_{d i}^{\text {ref }}=I_{d o}+V_{d o} G_{f}+\left(K_{P V}+K_{I V} / s\right)\left(V_{d o}^{r e f}-V_{d o}\right)-V_{q o} \omega C_{f} \\
& I_{q i}^{\text {ref }}=I_{q o}+V_{q o} G_{f}+\left(K_{P V}+K_{I V} / s\right)\left(V_{q o}^{r e f}-V_{q o}\right)+V_{d o} \omega C_{f}
\end{aligned}
$$

$$
\begin{aligned}
& e_{d}=V_{d o}+I_{d i} R_{f}+\left(K_{P A}+K_{I A} / s\right)\left(I_{d i}^{\text {ref }}-I_{d i}\right)-I_{q i} \omega L_{f} \\
& e_{q}=V_{q o}+I_{q i} R_{f}+\left(K_{P A}+K_{I A} / s\right)\left(I_{q i}^{\text {ref }}-I_{q i}\right)+I_{d i} \omega L_{f}
\end{aligned}
$$

$$
\left\{\begin{array}{l}
\therefore e_{d}=\left(V_{d o}+I_{d i} R_{f}-I_{q i} \omega L_{f}\right)+\left(\frac{K_{I A}+s K_{P A}}{s}\right) \times \\
\left(I_{d o}-I_{d i}+V_{d o} G_{f}+\frac{\left(K_{I V}+s K_{P V}\right)\left(V_{d o}^{r e f}-V_{d o}\right)}{s}-V_{q o} \omega C_{f}\right)
\end{array}\right.
$$

$$
\left\{\begin{array}{l}
\therefore e_{q}=\left(V_{q o}+I_{q i} R_{f}+I_{d i} \omega L_{f}\right)+\left(\frac{K_{I A}+s K_{P A}}{s}\right) \times \\
\left(\begin{array}{l}
I_{q o}-I_{q i}+V_{q o} G_{f}+\frac{\left(K_{I V}+s K_{P V}\right)\left(V_{q o}^{r e f}-V_{q o}\right)}{s}+V_{d o} \omega C_{f}
\end{array}\right)
\end{array}\right.
$$

$V_{p w m}^{r e f}=\left[\begin{array}{c}V_{a}^{r e f} \\ V_{b}^{r e f} \\ V_{c}^{\text {ref }}\end{array}\right]=\left[\begin{array}{ccc}\sin (\omega t) & \cos (\omega t) & 1 \\ \sin \left(-120^{\circ}+\omega t\right) & \cos \left(-120^{\circ}+\omega t\right) & 1 \\ \sin \left(120^{\circ}+\omega t\right) & \cos \left(120^{\circ}+\omega t\right) & 1\end{array}\right]\left[\begin{array}{c}e_{d} \\ e_{q} \\ e_{o}\end{array}\right]$

Further, from (5) and (6), it can be seen that the effectiveness of the reference PWM signal, thereby the V/I control system majorly depends upon the values of PIC gains $\left(K_{P A}, K_{I A}, K_{P V}, K_{I V}\right)$. Hence, it is intoned that the operation of the $\mathrm{V} / \mathrm{I}$ controller depends on the proper tuning of its PIC gains.

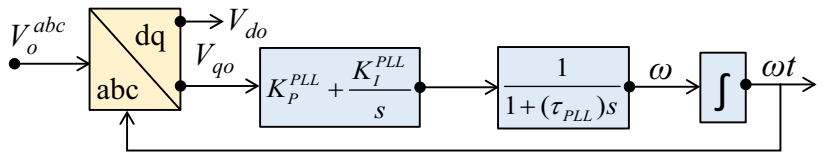

Fig. 3 Model of the phase-locked loop

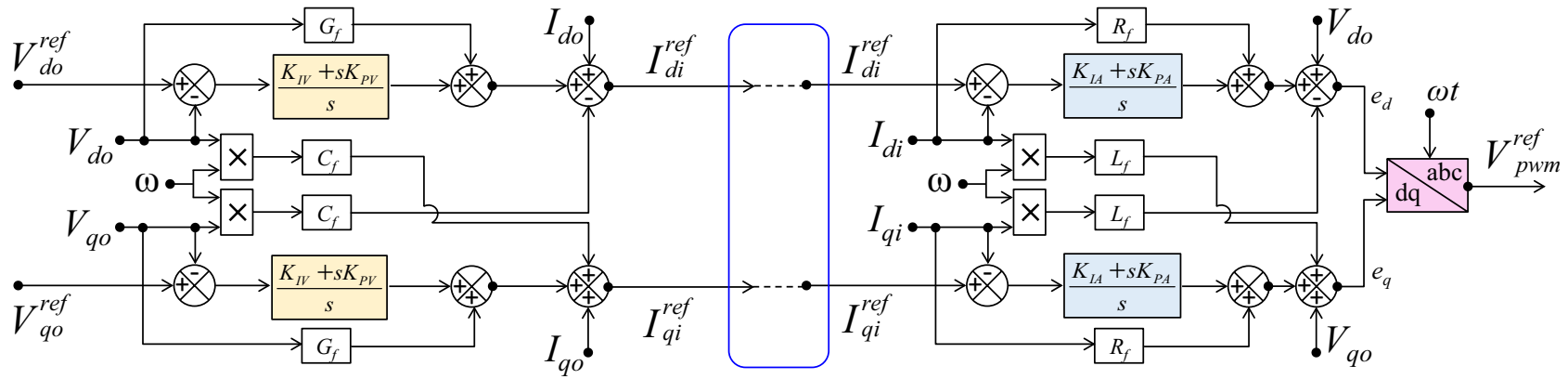

(a) Model of the voltage control module (b) Model of the current control module

Fig. 2 Models of voltage and current (V/I) controllers used for RESM control 
Table 1 Parameters used for the PLL design

\begin{tabular}{lll}
\hline Parameter & Description & Value \\
\hline$\tau_{P L L}$ & Time constant of PLL & $1 \mathrm{~ms}$ \\
$K_{P}^{P L L}$ & Proportional gain & 1.5476 \\
$K_{I}^{P L L}$ & Integral gain & 14.9814 \\
\hline
\end{tabular}

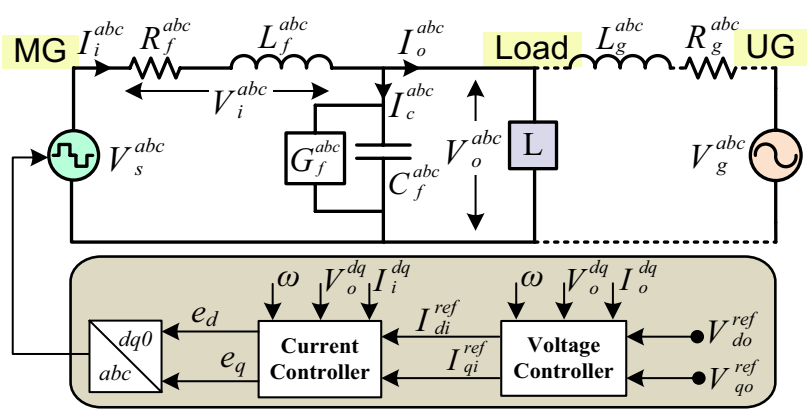

Fig. 4 Simplified circuit representation of the RESM plant

Table 2 Assumptions for the design of proposed method

\begin{tabular}{ll}
\hline S. No & Assumptions \\
\hline 1 & As the focus of the work is to improve tran- \\
& sient response that is affected due to load \\
& side dynamics, the source side dynamics \\
are not considered in the design. So, the \\
renewable energy sources and the PEVSI is \\
combined and considered as a simplified \\
single AC source $\left(V_{s}^{a b c}\right)$ as shown in Fig. 4 \\
In the design of the low-pass filter, the primary \\
focus is kept on the filter inductance $\left(L_{f}\right)$ and \\
capacitance $\left(C_{f}\right)$ parameters, which has a \\
critical impact on the RESM operation. As the \\
effect of filter resistance $\left(R_{f}\right)$ and conduct- \\
ance $\left(G_{f}\right)$ is negligible, these values are \\
chosen arbitrary minimum to simplify the \\
system transfer function
\end{tabular}

For the operation of $\mathrm{V} / \mathrm{I}$ controller, the phase-locked loop (PLL) is used for the calculation of a phase angle for $d-q$ transformation and the frequency of input voltage waveform. The block diagram of PLL is given in Fig. 3. Here, $a b c-d q$ transformation is used to get $V_{q o}, V_{d o}$; the $q$ and $d$ components of $V_{o}^{a b c}$ (voltage measured at the load bus). The modeling specifications given in Table 1 are used to design the PLL.

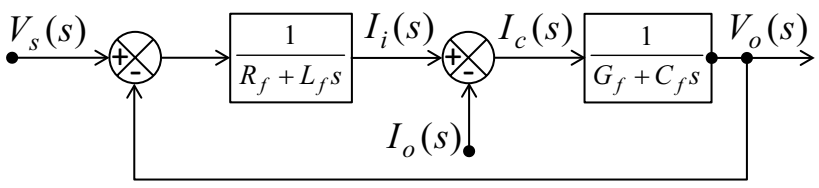

Fig. 5 Uncontrolled RESM plant model

\section{Development of the proposed small signal model of the microgrid}

The RESM schematic shown in Fig. 1 is represented as the simplified equivalent circuit shown Fig. 4 to develop its small signal model with respect to the assumptions given in Table 2. Here, UG and MG indicate the utility-grid and microgrid terminals, respectively. The objective of this model is to implement the proposed MPZC-based design method for the $\mathrm{V} / \mathrm{I}$ controller that controls the load voltage/outer-loop voltage $\left(V_{o}^{a b c}\right)$, and PEVSI's current/innerloop current $\left(l_{i}^{a b c}\right)$, whose single-phase parameters are represented as $V_{o}(s)$ and $l_{i}(s)$, respectively, and are related through (8)-(11). From (9) and (11), the uncontrolled microgrid plant model is obtained, as shown in Fig. 5, where the output and input are related as (12).

$V_{o}(s)=V_{s}(s)-V_{i}(s)$

$\therefore l_{i}(s)=\frac{V_{i}(s)}{R_{f}+s L_{f}}=\frac{V_{s}(s)-V_{o}(s)}{R_{f}+s L_{f}}$

$I_{i}(s)=I_{o}(s)+I_{c}(s) \Rightarrow I_{c}(s)=I_{i}(s)-I_{o}(s)$

$\therefore V_{o}(s)=\frac{I_{c}(s)}{G_{f}+C_{f} s}=\frac{I_{i}(s)-I_{o}(s)}{G_{f}+C_{f} s}$

$\Rightarrow V_{o}(s)=\frac{V_{s}(s)-\left(R_{f}+L_{f} s\right) I_{o}(s)}{1+\left(G_{f}+C_{f} s\right)\left(R_{f}+L_{f} s\right)}$

\subsection{Transfer function of the inner current controller}

The goal of the current controller is to regulate the current drawn from PEVSI $\left(I_{i}(s)\right)$. So, to derive the transfer function of the current controlled inner loop, the influence of the voltage controlled outer loop is ignored. The current controller model is developed as given in Fig. 6, where, 


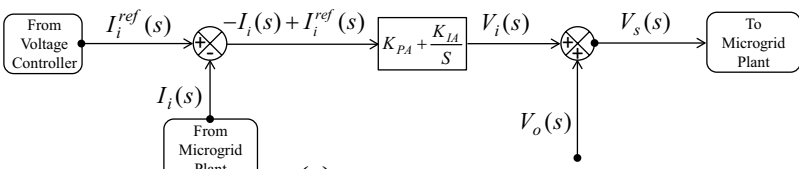

(a) Conceptual model

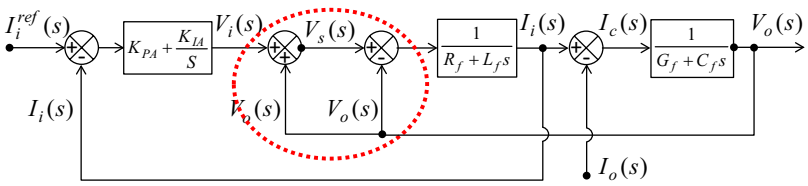

(b) Total model

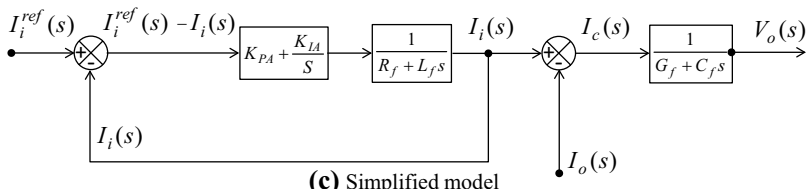

(c) Simplified model

Fig. 6 Model of the current controller of the RESM plant

Fig. $6 a$ gives the conceptual model to realize the current controller, Fig. $6 \mathrm{~b}$ shows its total model, and Fig. $6 \mathrm{c}$ shows its simplified model. From Fig. 6c, the CLTF and thereby, the controlled current is obtained as given in (13) and (14), respectively.

$$
\begin{aligned}
& \frac{l_{i}(s)}{I_{i}^{\text {ref }}}=\frac{\left(\frac{K_{I A}+K_{P A} s}{s\left(R_{f}+L_{f} s\right)}\right)}{1+\left(\frac{K_{I A}+K_{P A} s}{s\left(R_{f}+L_{f} s\right)}\right)}=\frac{K_{I A}+K_{P A} s}{s\left(R_{f}+L_{f} s\right)+K_{P A} s+K_{I A}} \\
& \left.\therefore I_{i}(s)\right|_{\text {innerloop }}=\frac{K_{P A} s+K_{I A}}{L_{f} s^{2}+\left(R_{f}+K_{P A}\right) s+K_{I A}} I_{i}^{\text {ref }} \\
& \frac{V_{o}(s)}{V_{o}^{\text {ref }}}=\frac{\left(\frac{K_{P V} s+K_{I V}}{s\left(G_{f}+C_{f} s\right)}\right)}{1+\left(\frac{K_{P V} s+K_{I V}}{s\left(G_{f}+C_{f} s\right)}\right)}=\frac{K_{P V} s+K_{I V}}{s\left(G_{f}+C_{f} s\right)+K_{P V} s+K_{I V}} \\
& \left.\therefore V_{o}(s)\right|_{\text {outerloop }}=\frac{K_{P V} s+K_{I V}}{C_{f} s^{2}+\left(G_{f}+K_{P V}\right) s+K_{I V}} V_{o}^{\text {ref }}
\end{aligned}
$$

\subsection{Transfer function of the outer voltage controller}

The goal of the voltage controller is to regulate the voltage across the load $\left(V_{o}(s)\right)$. So, to derive the transfer function of the voltage controlled outer loop, the effect of the current controlled inner loop is ignored. The voltage controller model is developed as given in Fig. 7, where, Fig. 7a gives the conceptual model to realize the voltage controller, Fig. 7b shows its total model, and Fig. 7c shows its simplified model. From Fig. 7c, the CLTF and thereby,

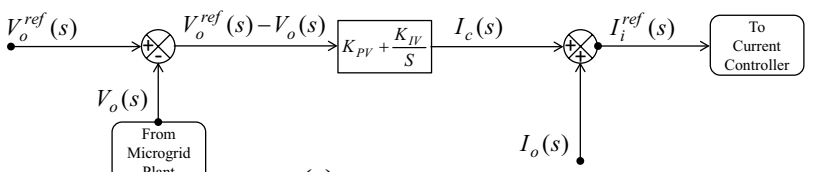

(a) Conceptual model

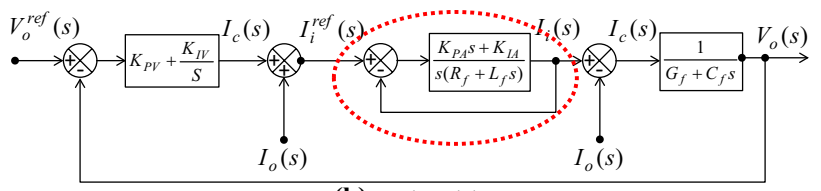

(b) Total model

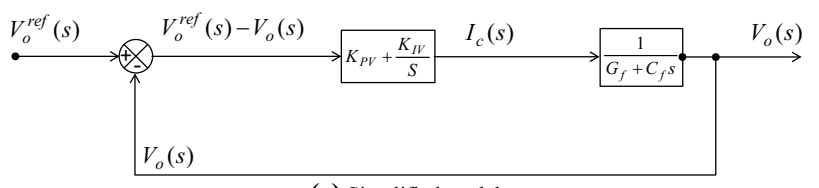

(c) Simplified model

Fig. 7 Model of the voltage controller of the RESM plant

the controlled voltage is obtained as given in (15) and (16), respectively.

\subsection{Transfer function of the overall microgrid system}

The V/I controllers' transfer function models are inserted into the uncontrolled plant model to develop the controlled plant model so that the controlled RESM plant model can be represented with a view of dual-control loops as denoted in Fig. 8. The output and input of this system are related through the transfer function given by (17). Equations (18) and (19) represent the OLTF and CLTF of the RESM plant, respectively. Hence, the small signal model of the microgrid plant is derived, as represented in Fig. 9, which is obtained based on (17)-(19). The integration of the three sub-models, viz., uncontrolled plant model given in Fig. 5, the current controller model given by Fig. 6 , and the voltage controller model given in Fig. 7 derive this overall model.

$\frac{V_{o}(s)}{V_{o}^{r e f}}=$ Closedloopof $\left(F_{1}(s) \times F_{2}(s) \times F_{3}(s)\right)$

where;

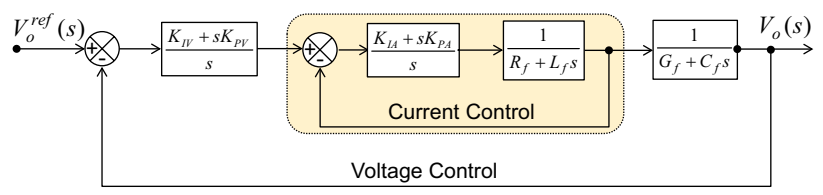

Fig. 8 Simplified dual-loop V/I controlled RESM model 


$$
\left\{\begin{array}{l}
F_{1}(s)=\frac{K_{I V}+s K_{P V}}{s} \\
F_{2}(s)=\text { Cl.loop }\left(\frac{K_{I A}+s K_{P A}}{s\left(s L_{f}+R_{f}\right)}\right)=\frac{K_{I A}+s K_{P A}}{s^{2} L_{f}+\left(R_{f}+K_{P A}\right) s+K_{I A}} \\
F_{3}(s)=\frac{1}{G_{f}+C_{f} s}
\end{array}\right.
$$$$
\left\{\begin{array}{l}
\therefore F_{1}(s) \times F_{2}(s) \times F_{3}(s)= \\
\frac{K_{P A} K_{P V} s^{2}+s\left(K_{P V} K_{I A}+K_{I V} K_{P A}\right)+K_{I A} K_{I V}}{\left(\begin{array}{l}
L_{f} C_{f} s^{4}+\left(C_{f} K_{P A}+G_{f} L_{f}+R_{f} C_{f}\right) s^{3} \\
+\left(G_{f} R_{f}+G_{f} K_{P A}+C_{f} K_{I A}\right) s^{2}+K_{I A} G_{f} s
\end{array}\right)}
\end{array}\right.
$$$$
\therefore \frac{V_{o}(s)}{V_{o}^{\text {ref }}}=\frac{\left(K_{P A} K_{P V}\right) s^{2}+\left(K_{I V} K_{P A}+K_{P V} K_{I A}\right) s+K_{I A} K_{I V}}{\left(\begin{array}{l}
\left(L_{f} C_{f}\right) s^{4}+\left(R_{f} C_{f}+G_{f} L_{f}+K_{P A} C_{f}\right) s^{3} \\
+\left(G_{f} R_{f}+K_{P A} G_{f}+K_{P V} K_{P A}+C_{f} K_{I A}\right) s^{2} \\
+\left(K_{P V} K_{I A}+G_{f} K_{I A}+K_{I V} K_{P A}\right) s+K_{I A} K_{I V}
\end{array}\right)}
$$

Fig. 9 Small signal model of the microgrid plant involving $\mathrm{V} / \mathrm{I}$ controllers

\section{Tuning of the $V / I$ controller parameters}

By the observation of small signal model shown in Fig. 9, the system control depends upon two parameters, viz., filter parameters $\left(R_{f} L_{f}, C_{f}, G_{f}\right)$ and PIC parameters of V/I controller $\left(K_{P V}, K_{I V}, K_{P A}, K_{I A}\right)$. Hence, the proper design of these parameters improves the RESM's response. With this intent, this section focuses on the tuning methods of controller parameters. The filter specifications are designed based on the relations expressed in (20) and (21) [40]. The computed values and the other considerations are given in Table 3.

$C_{f}=\frac{2 P_{r}}{F_{s} V_{d c}\left(\Delta V_{a c}\right)}$

$L_{f}=\frac{1}{\left(2 \pi F_{r}\right)^{2} C_{f}}$

where $\Delta V_{a c}$ and $F_{r}$ are chosen as per the power quality requisites given by IEEE-1547, IEEE-519 standards.

Table 3 Parameters used for the controller design/testing

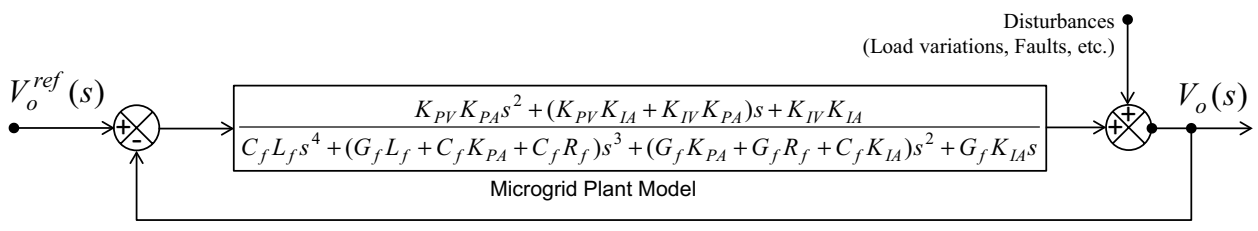

\begin{tabular}{lll}
\hline Parameter & Description & Specification \\
\hline$P_{r}+\mathrm{j} Q_{r}$ & Rated power of RESM & $25 \mathrm{~kW}+\mathrm{j} 25 \mathrm{kVAR}$ \\
$V_{d c}$ & PEVSI's input DC voltage & $540 \mathrm{~V}$ \\
$\Delta V_{a c}$ & Maximum deviation allowed in the PEVSI output voltage & $\pm 62 \mathrm{~V}$ \\
$F_{s}$ & Switching frequency used for producing PEVSI's PWM signals & $15 \mathrm{kHz}$ \\
$F_{r}$ & Minimum ripple frequency component exist in the grid current & $600 \mathrm{~Hz}$ \\
$C_{f}$ & Capacitance used for filter design & $50 \mu \mathrm{F}$ \\
$L_{f}$ & Inductance used for filter design & $1.35 \mathrm{mH}$ \\
$R_{f}$ & Resistance used for filter design & $0.1 \Omega$ \\
$G_{f}$ & Conductance used for filter design & $0 \widetilde{ }$
\end{tabular}

Table 4 Steps involved in OLTR and EPI tuning methods

Step-1 Remove all the feedback/feedforward loops and the controller from the plant, so that no control action involved in the plant response

Step-2 Excite the plant with a step input and observe its open-loop response as referred in Fig. 10

Step-3 By using the inflection point as the basis, draw the tangent to this open-loop curve. From this, measure the value of dead time $\left(T_{d}\right)$, time constant $\left(\tau_{c}\right)$, stationary gain $\left(K_{s}\right)$, and tangent slope $(M)$

Step-4 Compute the PI specifications using Tables 5 and $6[41,42]$. The corresponding computed values are given in Table 7 


\subsection{Conventional methods for tuning $\mathrm{V} / \mathrm{I}$ controller gain}

Among many conventional tuning methods as discussed in Sect. 1, more suitable methods such as OLTR and EPI methods (which were widely used in the literature for similar applications and can exhibit tolerable transient stability responses) are chosen to validate the proposed method against them. These OLTR and EPI methods work on the plant's open-loop response with respect to design procedural steps given in Table $4[17,41,42]$. As the RESM's controller involves $\mathrm{V} / \mathrm{I}$ dual-loops, the tuning steps given in Table 4 has to be repeated for those two loops. The limitations of these conventional OLTR and EPI methods are given as follows.

- Due to the presence of interdependent dual control loops, as mentioned above, the use of these conventional methods for RESM application is quite questionable.

- The measured parameters $\left(T_{d^{\prime}} \tau_{c^{\prime}} K_{s^{\prime}} M\right)$ from the openloop response as described in Table 4 need to be more accurate for precise design of PIC gain parameters.

- By considering the limitations described above, Sect. 5.1 gives a quantitative analysis to understand the applicability of these conventional methods to RESMs application.

\subsection{Proposed method for tuning V/I controller gains}

This section describes the development of the proposed MPZC method for the tuning of $\mathrm{V} / \mathrm{I}$ controllers' parameters as below.

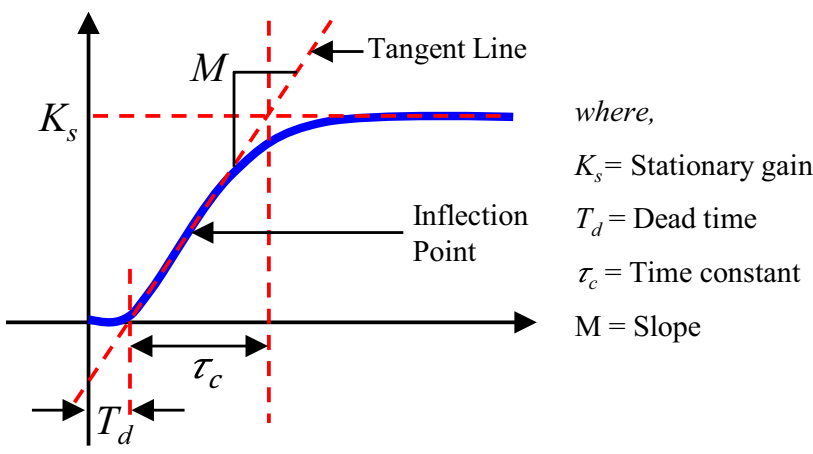

Fig. 10 Open-loop response curve
Table 5 Formulae to tune PIC by OLTR and EPI methods

\begin{tabular}{lll}
\hline Method & Proportional gain $\left(K_{p}\right)$ & Integral time constant $\left(T_{i}\right)$ \\
\hline ZN-1 & $0.9 / M T_{d}$ & $3.3 T_{d}$ \\
WJC & $\left(0.73+\frac{0.53 \tau_{c}}{T_{d}}\right) \frac{\left(\tau_{c}+0.5 T_{d}\right)}{K_{s}\left(\tau_{c}+T_{d}\right)}$ & $\tau_{c}+0.5 T_{d}$ \\
CHR & $0.35 / M T_{d}$ & $1.2 T_{d}$ \\
CC & $\frac{0.9}{M T_{d}}\left(1+\frac{0.92 \tau_{c}}{1-\tau_{c}}\right)$ & $\frac{3.3-3 \tau_{c}}{1+1.2 \tau_{c}} T_{d}$ \\
EPI & $\frac{a_{1}}{K_{s}}\left(\frac{T_{d}}{\tau_{c}}\right)^{b_{1}}$ & $\tau_{c}\left(a_{2}+b_{2}\left(\frac{T_{d}}{\tau_{c}}\right)\right)^{-1}$ \\
\hline
\end{tabular}

\subsubsection{Procedure for tuning current controller parameters}

From the simplified current controller model realized in Fig. $6 c$, the OLTF for controlling the inner-loop current or current drawn from the PEVSI $\left(I_{i}(s)\right)$ is obtained as (22). From this, the open-loop poles of the current controller model are obtained as $(0)$ and $\left(-R_{f} / L_{f}\right)$, where, one pole $(s=0)$ represents marginal stability, and another pole $\left(s=-R_{f} / L_{f}\right)$ represents near marginal stability due to very lower $\left(R_{f}\right)$ value for RESMs as explained in Table 2. Hence, these two poles lead to sluggish plant's response and thereby, exhibits poor transient response during disturbances. The issue mentioned above can be alleviated by the proposed MPZC method. To achieve this, it is proposed to consider (23), so that the near marginal stable pole gets cancelled with the zero. The near marginal stable pole is a dominant pole, which is responsible for the system dynamics. The idea of compensating the effect of this dominant pole highly influences the dynamics of the closed-loop system. The resultant OLTF is obtained as (24), where the second-order system (22) is transformed to a first-order system. This exhibits improved transient responses by damping out the natural oscillatory response of second-order systems. Further, (25) denotes the CLTF of the current controller used to design its gain parameters.

$\left.\frac{I_{i}(s)}{I_{i}^{r e f}}\right|_{\text {openloop }}=\frac{K_{I A}+s K_{P A}}{s\left(R_{f}+s L_{f}\right)}=\frac{K_{P A}}{s L_{f}}\left(\frac{s+\left(K_{I A} / K_{P A}\right)}{s+\left(R_{f} / L_{f}\right)}\right)$

Table 6 Design constants used in EPI tuning methods

\begin{tabular}{lrrrr}
\hline Criterion & \multicolumn{1}{l}{ ISE } & \multicolumn{1}{l}{ ISTSE } & \multicolumn{1}{l}{ ISTE } & \multicolumn{1}{l}{ ITAE } \\
\hline $\mathrm{a}_{1}$ & 1.048 & 0.968 & 1.042 & 0.965 \\
$\mathrm{a}_{2}$ & 1.195 & 0.977 & 0.987 & 0.796 \\
$\mathrm{~b}_{1}$ & -0.897 & -0.904 & -0.897 & -0.85 \\
$\mathrm{~b}_{2}$ & -0.368 & -0.253 & -0.238 & -0.1465 \\
\hline
\end{tabular}


Table 7 V/I Controller gains tuned by OLTR/EPI methods

\begin{tabular}{|c|c|c|c|c|c|c|}
\hline \multirow[t]{2}{*}{ Method } & \multicolumn{3}{|c|}{ Current controller } & \multicolumn{3}{|c|}{ Voltage controller } \\
\hline & $K_{P A}$ & $T_{I A}$ & $K_{I A}$ & $K_{P V}$ & $T_{I V}$ & $K_{I V}$ \\
\hline \multicolumn{7}{|c|}{ OLTR Methods $\left(T_{d}(s)=0.01 ; \tau_{c}(s)=0.0164 ; K_{s}=10 ; M=609.76\right)$} \\
\hline ZN-1 & 0.015 & 0.033 & 4.473 & $9 e^{-4}$ & 0.33 & $27.3 e^{-4}$ \\
\hline WJC & 0.129 & 0.021 & 6.065 & $3.66 \mathrm{e}^{-4}$ & 0.05 & $73.2 e^{-4}$ \\
\hline $\mathrm{CHR}$ & 0.057 & 0.012 & 4.783 & $3.5 \mathrm{e}^{-4}$ & 0.12 & $29.2 e^{-4}$ \\
\hline CC & 0.149 & 0.032 & 4.702 & $9 e^{-4}$ & 0.33 & $27.3 e^{-4}$ \\
\hline \multicolumn{7}{|c|}{ EPI Methods $\left(T_{d}(s)=0.1 ; \tau_{c}(s)=1.5 \times 10^{-4} ; K_{s}=1 \times 10^{3} ; M=1 \times 10^{4}\right)$} \\
\hline ISE & 0.163 & 0.017 & 9.665 & $3.07 \mathrm{e}^{-6}$ & $-6.14 \mathrm{e}^{-7}$ & -5 \\
\hline ISTE & 0.162 & 0.019 & 8.331 & $3.05 \mathrm{e}^{-6}$ & $-9.51 e^{-7}$ & -3.207 \\
\hline ISTSE & 0.151 & 0.019 & 7.595 & $2.71 e^{-6}$ & $-8.95 e^{-7}$ & -3.028 \\
\hline ITAE & 0.147 & 0.023 & 6.329 & $3.84 \mathrm{e}^{-6}$ & $-1.55 e^{-6}$ & -2.476 \\
\hline
\end{tabular}

Assume $\frac{K_{I A}}{K_{P A}}=\frac{R_{f}}{L_{f}}$

$\left.\Rightarrow \frac{I_{i}(s)}{l_{i}^{\text {ref }}}\right|_{\text {openloop }} ^{M P Z C}=\frac{K_{P A}}{s L_{f}}$

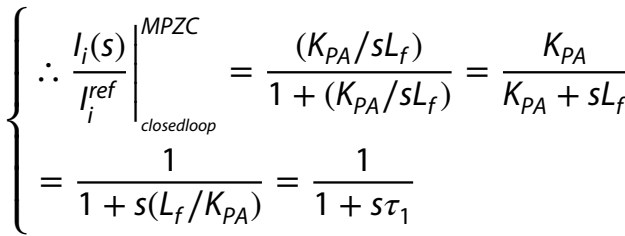

where $\left(\tau_{1}=L_{f} / K_{P A}\right)$ represents the current controller's time constant (or V/I controller's inner-loop time constant). Hence, from (23) and (25), current controller's parameters $\left(K_{P A}, K_{I A}\right)$ are computed by selecting proper filter parameters $\left(R_{f}, L_{f}\right)$ as given in Table 3 and suitable lower time constant $\left(\tau_{1}\right)$. The resultant calculated values are given in Table 8.

\subsubsection{Procedure for tuning voltage controller parameters}

From the simplified voltage controller model realized in Fig. 7c, the OLTF for controlling the outer-loop voltage or load voltage $\left(V_{o}(s)\right)$ is obtained as (26). This includes $G_{f}=0$ as given in Table 3 , as it is already mentioned that the effect of $G_{f}$ is negligible for RESMs application. Equation (26) represents a second-order system transfer function with two poles at the origin. This leads to severe oscillatory responses due to having marginal stability characteristics, which may become unstable for specific conditions and stable for certain other conditions. The issue mentioned above can be alleviated by the proposed MPZC method. To realize this, it is proposed to consider (27), which cancels one pole at the origin. The resultant OLTF is derived as (28), where the second-order system (26) is transformed to firstorder system. This exhibits improved transient response by damping out the severe oscillatory responses, as mentioned above. Further, (29) gives the CLTF of the voltage controller that is used to design its gain parameters.

$\left.\frac{V_{o}(s)}{V_{o}^{\text {ref }}}\right|_{\text {openloop }}=\left(K_{P V}+\frac{K_{I V}}{s}\right)(\overbrace{\underbrace{\frac{1}{G_{f}}+C_{f} s}_{=0}}^{1 / C_{f} s})=\frac{K_{P V} s+K_{I V}}{C_{f} s^{2}}$

Assume the Voltage controller's Integral Gain

$K_{I V}=0$

$\left.\Rightarrow \frac{V_{o}(s)}{V_{o}^{r e f}}\right|_{\text {openloop }} ^{M P Z C}=\frac{K_{P V}}{C_{f} s}$
Table 8 Computed parameters of $\mathrm{V} / \mathrm{I}$ controllers

\begin{tabular}{lll}
\hline Parameter & Description & Value \\
\hline$\tau_{1}$ & Current control-inner loop time constant & $15 \mathrm{~ms}$ \\
$\tau_{2}$ & Voltage control-outer loop time constant & $90 \mathrm{~ms}$ \\
$K_{P A}$ & Proportional controller specification of the current controller & 0.12 \\
$K_{I A}$ & Integral controller specification of the current controller & 6.7 \\
$K_{P V}$ & Proportional controller specification of the voltage controller & $5.65 \mathrm{e}^{-4}$ \\
$K_{I V}$ & Integral controller specification of the voltage controller & 0 \\
\hline
\end{tabular}


$\left\{\begin{array}{l}\left.\therefore \frac{V_{o}(s)}{V_{o}^{\text {ref }}}\right|_{\text {closedloop }} ^{M P Z C}=\frac{\left(K_{P V} / s C_{f}\right)}{1+\left(K_{P V} / s C_{f}\right)}=\frac{K_{P V}}{s C_{f}+K_{P V}} \\ =\frac{1}{1+s\left(C_{f} / K_{P V}\right)}=\frac{1}{1+s \tau_{2}}\end{array}\right.$

where $\left(\tau_{2}=C_{f} / K_{P V}\right)$ represents the voltage controller's time constant (or V/I controller's outer-loop time constant). Hence, from (29), tuning of $K_{P V}$ of the voltage controller is achieved by selecting suitable time constant $\left(\tau_{2} \geq 5 \tau_{1}\right)$ and filter parameter $\left(C_{f}\right)$ given in Table 3. The resultant computed value is given in Table 8 .

\subsection{Rationale of the proposed MPZC method}

The overall system's CLTF given by (19) can be implemented with the parameter values obtained with respect to the conventional and proposed control methods discussed in Sects. 4.1 and 4.2. Hence, by substituting these parameter values given in Tables 3, 7, and 8 , the system transfer function can be revised as given in (30) and (31) with respect to the conventional CC method and proposed MPZC method. From there, it can be understood that the use of the proposed MPZC method reduces the system size (order), which leads to the improvement of its transient response.

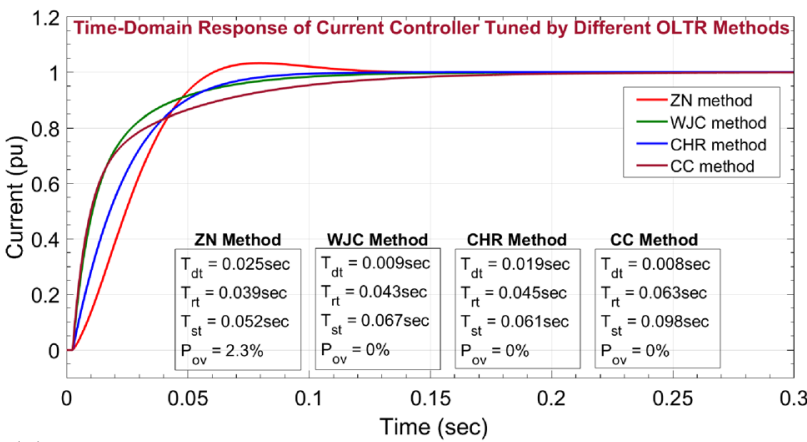

(a) Time-domain responses of single-loop RESM with OLTR methods

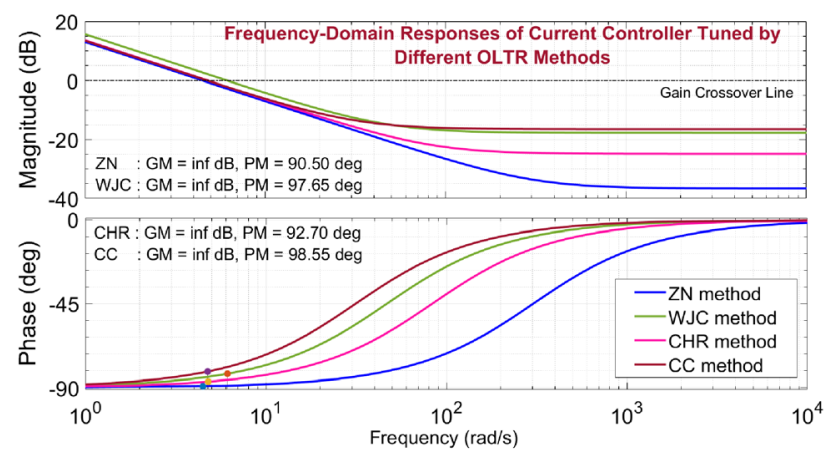

(c) Stability response plots of single-loop RESM with OLTR methods

$$
\left.\frac{V_{o}(s)}{V_{o}^{r e f}}\right|^{C C}=\frac{1.99 s^{2}+68.72 s+190.17}{0.001 s^{4}+0.18 s^{3}+5.47 s^{2}+68.72 s+190.17}
$$

$\left.\frac{V_{o}(s)}{V_{o}^{r e f}}\right|^{M P Z C}=\frac{s+56.08}{0.001 s^{3}+0.163 s^{2}+5.97 s+56.08}$

\section{Comparative results and analysis}

As per the objective of the paper, the results are segregated into two parts for the analysis, viz., (i) quantitative analysis on the applicability of conventional methods for RESMs, and (ii) comparative analysis of proposed and conventional methods subjected to various test conditions.

\subsection{Analysis on the applicability of conventional tuning methods for microgrids}

As discussed in Sect. 4.1, conventional methods, viz., OLTR (ZN-1, WJC, CHR, CC) and EPI (ISE, ISTE, ISTSE, IATE) are tested for their applicability to RESM. The efficacy of these methods is assessed in two test modes, viz., one is when

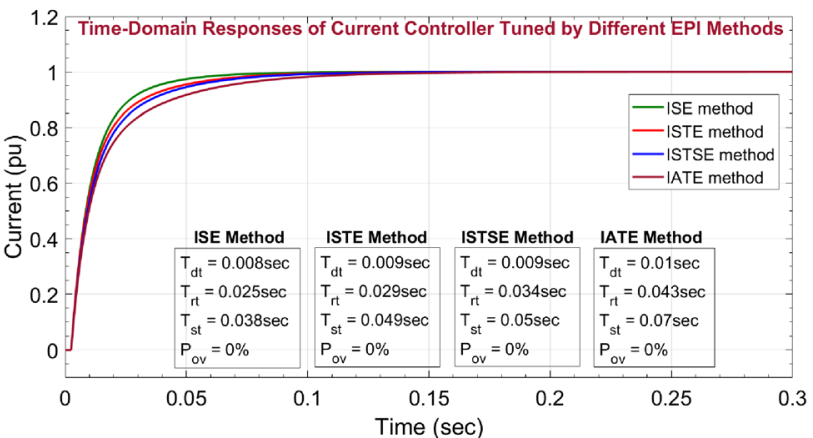

(b) Time-domain responses of single-loop RESM with EPI methods

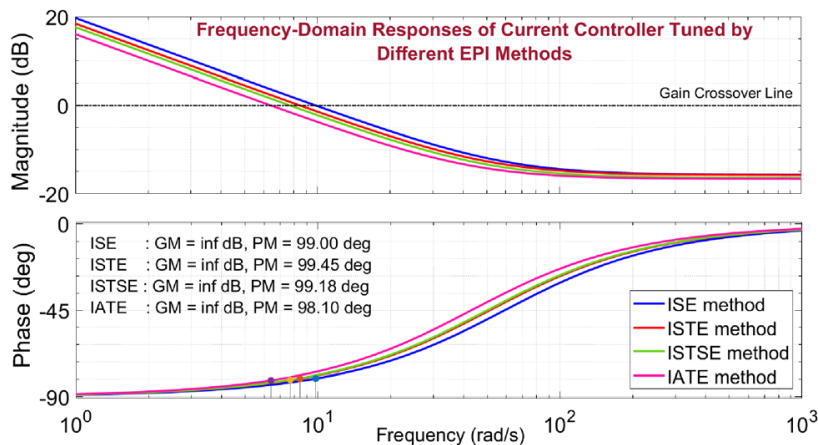

(d) Stability response plots of single-loop RESM with EPI methods

Fig. 11 Response of the single-control loop system (current controller based RESM) with conventional OLTR and EPI methods 

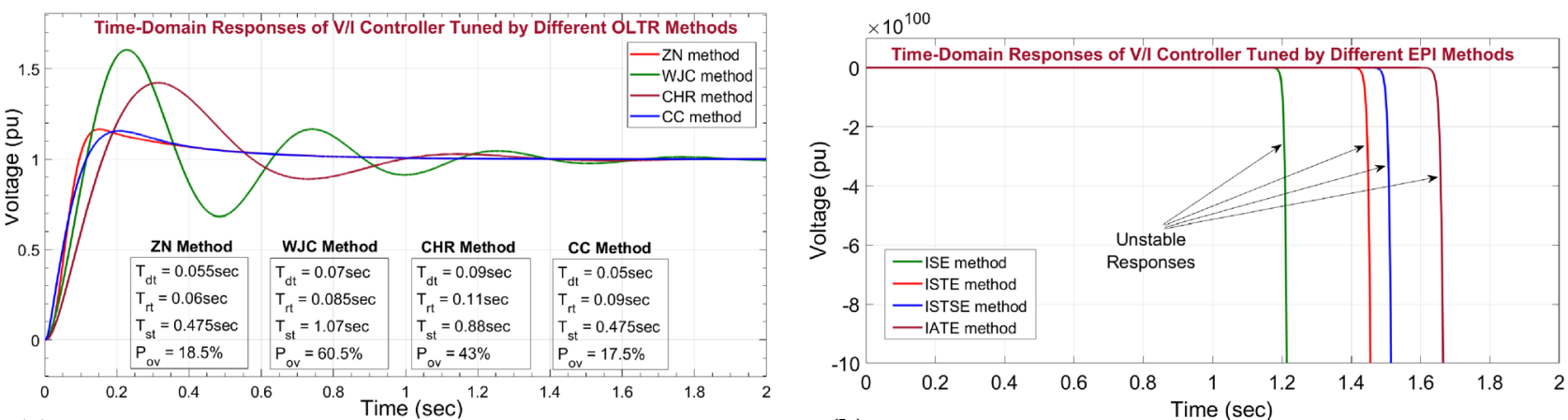

(a) Time-domain responses of dual-loop RESM with OLTR methods

(b) Time-domain responses of dual-loop RESM with EPI methods
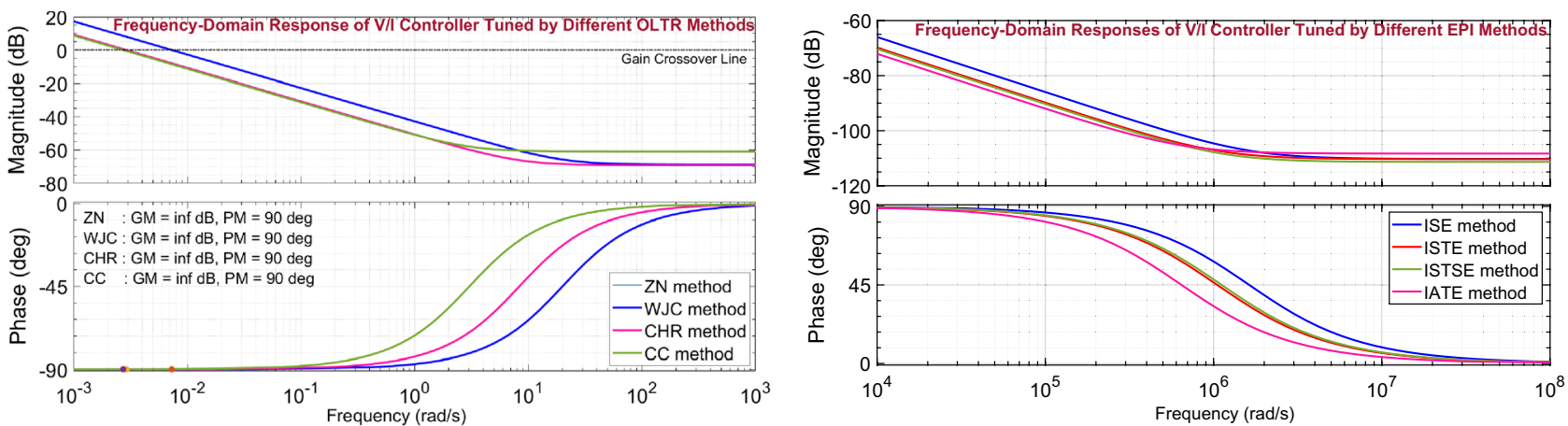

(c) Stability response plots of dual-loop RESM with OLTR methods

(d) Stability response plots of dual-loop RESM with EPI methods

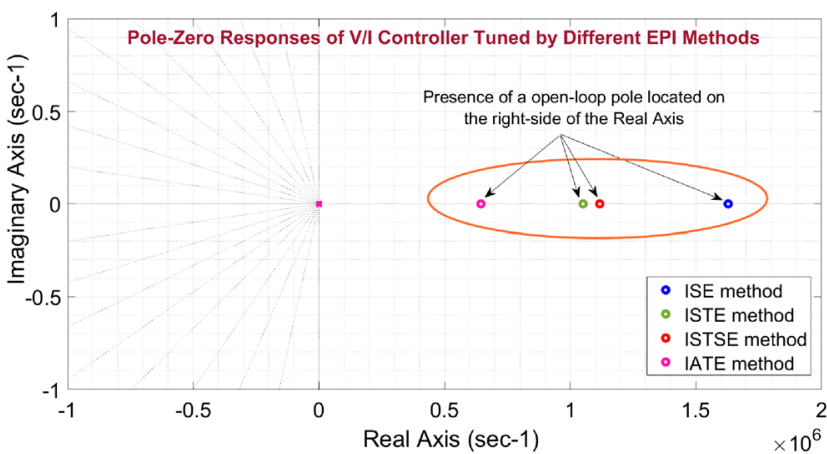

(e) Pole-Zero plot of dual-control loop based RESM with EPI methods

Fig. 12 Response of the dual-control loop system (V/I controller based RESM) with conventional OLTR and EPI methods

using for parameter tuning in the single-loop system, i.e., only the current controller (or inner-loop) based RESM and another is when using for parameter tuning in dual-loop system, i.e., for V/I controller-based RESM. In both the test modes, time-domain and frequency-domain responses are plotted during the normal condition (no disturbance) as shown in Fig. 11 and Fig. 12 to understand the applicability of OLTR and EPI methods to RESMs. Various time-domain index (viz., delay time $\left(T_{d t}\right)$, rise time $\left(T_{r t}\right)$, settling time $\left(T_{s t}\right)$, peak-overshoot $\left(P_{\text {ov }}\right)$ ) and frequency-domain index (viz., phase margin (PM), gain margin (GM)) are computed to identify the superior method among these conventional methods. From these results, the following remarks could be noted.

- For the single-control loop-based system From Fig. 11, it is observed that all the conventional OLTR and EPI tuning methods worked satisfactorily as per the computed frequency/time-domain performance index.

- For the dual-control loop-based system From Fig. 12a, c, it is observed that the OLTR methods worked satisfactorily. But, From Fig. 12b, d, it is clear that the EPI meth- 
Table 9 Performance comparison of OLTR and EPI methods

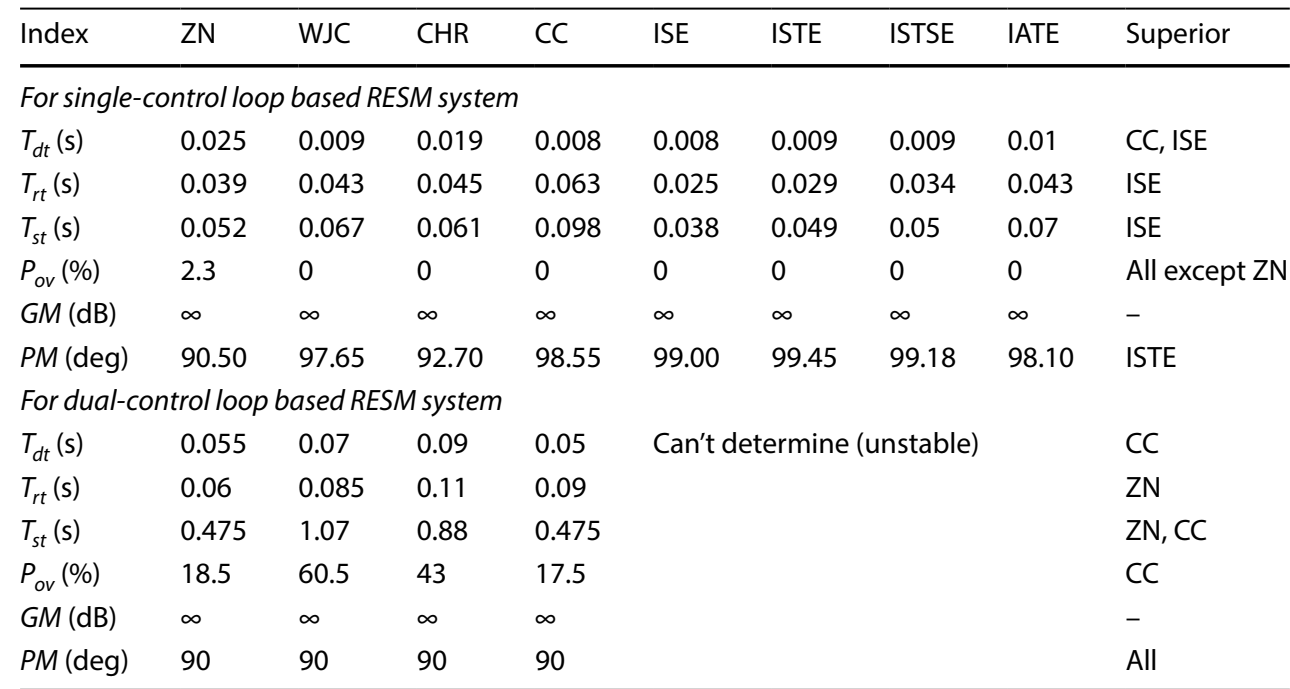

ods which worked well for single-control loop-based system are failed for dual-control loop system and leads to instability.

The corresponding performance index is also undetermined from Fig. 12b, d. Hence, a pole-zero plot is drawn, as shown in Fig. 12e to observe the location of poles. Form this, it is seen that, EPI methods lead to the existence of open-loop pole (or closed-loop zero) located on the very far right-half of s-plane, which represents an unstable system.

As it is advised by IEEE-1547, IEEE-519 standards to use both V/I control loops for robust RESM operation during transients, and based on the observations described above, it is concluded that the EPI methods are not suitable for RESMs application. Further, from Table 9, it is understood that the CC method shows better response in most of the index compared to other methods. Hence, the CC method is considered to assess the usefulness of the proposed MPZC method when subjected to different test conditions.

\subsection{Comparative analysis of the proposed method and conventional method}

To justify the efficacy of the proposed method, different test cases referred in Table 10 are applied, and the corresponding results of proposed MPZC method and conventional best (CC) method are compared. These test cases are considered in a way to resemble practical smoothly varying reactive load as well as largely varying nonlinear load (e.g., arc furnace, welding machines, etc.). The resultant simulation results are shown through Fig. 13, 14, 15 and 16 and the collective quantitative comparisons with respect to the standard tolerances are provided in Table 11.

Test case- $T_{1}$ (of Table 10) is used to examine the stabilization capacity of the RESM system subjected to conventional and proposed methods. For analysis, time-domain and frequency-domain responses are plotted as given in Fig. 13. From Fig. 13a, it is seen that, even with more rise time, the proposed method leads to smooth response with faster settling time compared to the conventional method. Another major benefit is that it exhibits zero overshoot at startup, while it is dominant (18.5\%) when using the conventional method. Similarly, from the frequency-domain
Table 10 Test cases implemented for comparative analysis

\begin{tabular}{lll}
\hline Case & Condition & Specifications/description \\
\hline $\mathrm{T}_{1}$ & No disturbance & Normal operating condition \\
$\mathrm{T}_{2}$ & Momentary huge reactive load ON & Inject a sinusoidal voltage (ampli- \\
& tude $=0.5 \mathrm{pu}$, frequency $=10 \mathrm{~Hz}$, \\
& sampling time $=0.01 \mathrm{~s})$ during \\
& $(1.2-1.4) \mathrm{s}$ \\
$\mathrm{T}_{3}$ & Inject a band-limited white noise \\
& disturbance (amplitude $= \pm 1 \mathrm{pu}$ \\
& varying, sampling time $=5 \mathrm{~ms})$ dur- \\
& ing $(1.2-1.4) \mathrm{s}$ \\
\hline
\end{tabular}


Table 11 Quantitative comparison of outcomes achieved with proposed and conventional methods

\begin{tabular}{|c|c|c|c|c|c|}
\hline \multicolumn{2}{|c|}{ Performance Comparison Index } & \multirow{2}{*}{$\begin{array}{l}\text { Result identifier } \\
\text { Test: } T_{1} \text {, Fig. } 13\end{array}$} & \multirow{2}{*}{$\begin{array}{l}\begin{array}{l}\text { Conventional CC } \\
\text { method }\end{array} \\
0.05\end{array}$} & \multirow{2}{*}{$\begin{array}{l}\text { Proposed MPZC } \\
\text { method }\end{array}$} & \multirow[t]{2}{*}{ Standard tolerance } \\
\hline Stability Performance & Delay time $\left(T_{d t}\right)(\mathrm{s})$ & & & & \\
\hline & Rise time $\left(T_{r t}\right)(\mathrm{s})$ & & 0.075 & 0.14 & \\
\hline & Settling time $\left(T_{s t}\right)(\mathrm{s})$ & & 0.45 & 0.23 & \\
\hline & $\begin{array}{l}\text { Peak-overshoot }\left(P_{\text {ov }}\right) \\
(\%)\end{array}$ & & 18.5 & 0 & \\
\hline & Gain margin $(\mathrm{dB})$ & & $\infty$ & $\infty$ & \\
\hline & Phase margin (deg) & & 90.0 & 97.2 & \\
\hline \multirow{5}{*}{$\begin{array}{l}\text { Frequency Character- } \\
\text { istics }\end{array}$} & Over-frequency (Hz) & Test: $T_{2}$, Fig. 14 & 50.18 & 50.04 & \multirow{4}{*}{$\begin{array}{l}\text { Over- } 51 \mathrm{~Hz} \text {, Under- } \\
49 \mathrm{~Hz} \\
( \pm 2 \% \text { of } 50 \mathrm{~Hz})(\mathrm{DZS} \\
387-1, \text { IEC } 61727 \\
\text { IEEE 1547) }\end{array}$} \\
\hline & & Test: $T_{3}$, Fig. 16 & 50.13 & 50.06 & \\
\hline & Under-frequency (Hz) & Test: $T_{2}$, Fig. 14 & 49.84 & 49.94 & \\
\hline & & Test: $T_{3}$, Fig. 16 & 49.91 & 49.94 & \\
\hline & $d f / d t(\mathrm{~Hz} / \mathrm{sec})$ & Test: $T_{2}$, Fig. 14 & $+1.82,-1.42$ (violated) & $+0.61,-0.46$ & $\pm 1 \mathrm{~Hz} / \mathrm{sec}(\mathrm{IEC} 61727)$ \\
\hline \multirow[t]{6}{*}{ Voltage Characteristics } & $d V / d t(\mathrm{~V} / \mathrm{sec})$ & Test: $T_{2}$, Fig. 14 & $+4.4,-6.6($ violated $)$ & $+1.1,-2.6$ & $\pm 3 \mathrm{~V} / \mathrm{sec}(\mathrm{ANSI} 27 / 59)$ \\
\hline & Over-voltage (\%) & Test: $T_{2}$, Fig. 15 & 4.92 & 1.19 & \multirow{2}{*}{$\begin{array}{l}\text { 10\% (EN 50160, IEEE } \\
1547.2 \text { ) }\end{array}$} \\
\hline & Under-voltage (\%) & Test: $T_{2}$, Fig. 15 & 9.05 & 1.75 & \\
\hline & THD content (\%) & Test: $T_{2}$, Fig. 15 & 3.30 & 0.77 & \multirow{2}{*}{$\begin{array}{l}\text { 5\% (IEEE 519, IEEE 929- } \\
\text { 2000, IEEE 1547) }\end{array}$} \\
\hline & & Test: $T_{3}$, Fig. 16 & 5.37 (violated) & 1.21 & \\
\hline & Waveshape & Test: $T_{3}$, Fig. 16 & Huge variation & Smooth & Smooth (IEEE 1547) \\
\hline
\end{tabular}

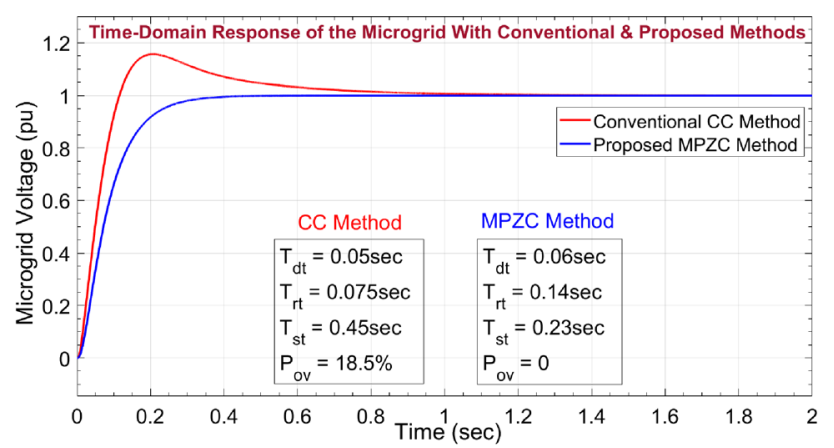

(a) Time-domain responses with conventional \& proposed methods

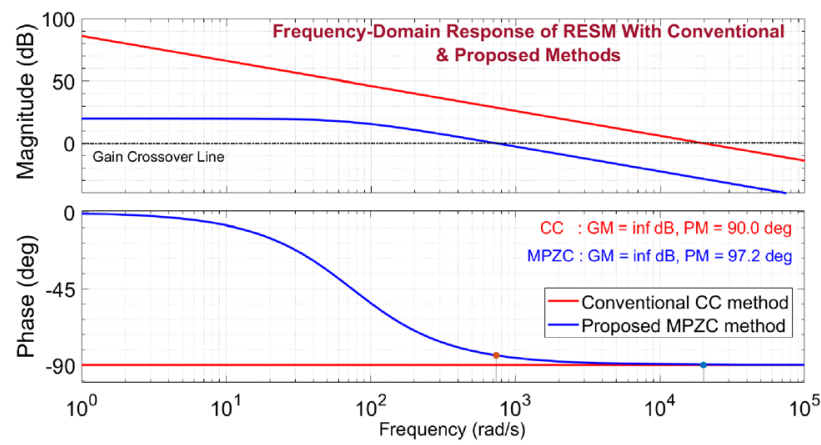

(b) Frequency-domain responses with conventional \& proposed methods

Fig. 13 Voltage responses of the RESM as per test case- $\mathrm{T}_{1}$

response shown in Fig. 13b, it is witnessed that the phase margin is increased from $90^{\circ}$ to $97.2^{\circ}$ when using the proposed method. This increase in the stability margin boosts the RESM system's stabilization capacity during transients.
Test cases- $\mathrm{T}_{2}$ and $\mathrm{T}_{3}$ (of Table 10) are used to analyze the system response during disturbances. For the analysis, various voltage characteristic index [viz., waveshape, rate of change of voltage ( $d v / d t)$, over-voltage, under-voltage, total harmonic distortion (THD)] and frequency characteristic index [viz., under-frequency, over-frequency, rate of change of frequency $(d f / d t)$ ] are obtained. In Test case- $T_{2}$, a disturbance of very low frequency $(10 \mathrm{~Hz})$ compared to nominal frequency $(50 \mathrm{~Hz})$ is injected as shown in Fig. 14a and in Test case- $\mathrm{T}_{3}$, a nonlinear disturbance of \pm 1 pu varying magnitude is injected as shown in Fig. 16a for the comparative study of conventional and proposed methods. From the frequency characteristics given in Figs. 14b and $16 \mathrm{~b}$, it is witnessed that the proposed method noticeably decreased the frequency deviation from its rated value compared to the conventional method. Also, from Fig. 14b, it is noticed that the use of conventional method causes a huge $d f / d t$ of $1.82 \mathrm{~Hz} / \mathrm{sec}$, which exceeds the standard limit of $\pm 1 \mathrm{~Hz} / \mathrm{sec}$ as given in Table 11 . This is a severe issue that can result in unwanted load shedding or loss of utility-grid connection, concerns with phase balancing, real-power balancing, power hums/electromagnetic interferences for domestic appliances, etc. On the other side, the proposed method reduced the $d f / d t$ from 1.82 to $0.61 \mathrm{~Hz} / \mathrm{sec}$, which adheres the standard limit of $\pm 1 \mathrm{~Hz} / \mathrm{sec}$. This helps in improving the transient frequency response and can address the majority of the concerns mentioned above. Also, from Fig. $14 \mathrm{c}$, it is noticed that the $d v / d t$ is significantly reduced when using the proposed method. 


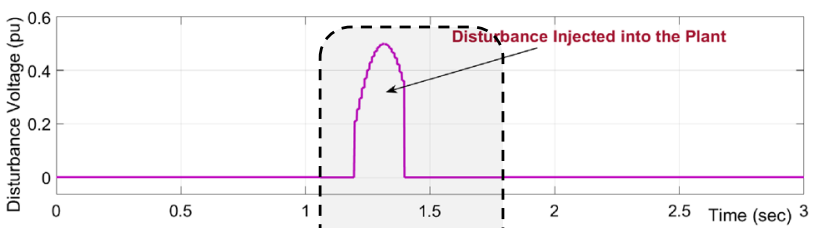

(a) Injected disturpance of very low ffequency $(10 \mathrm{~Hz})$

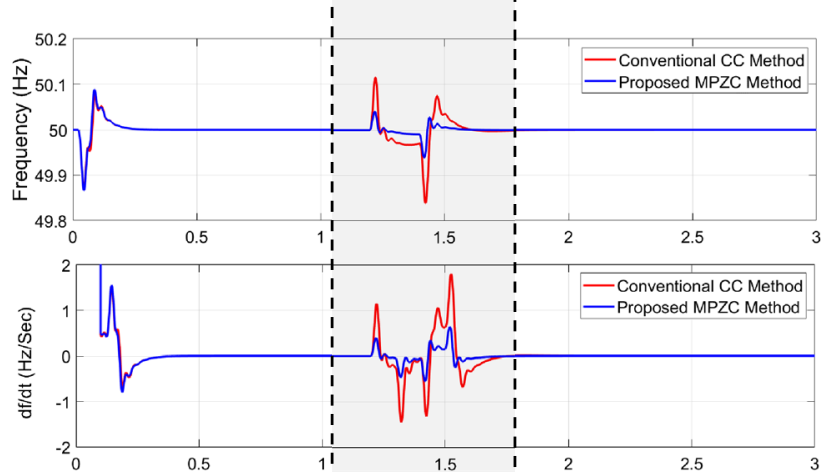

(b) Frequency response with respect to the applied disturbance

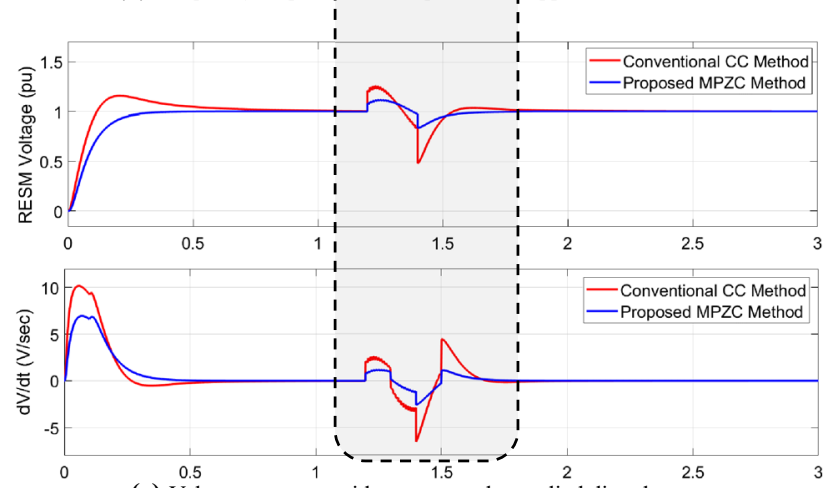

(c) Voltage response with respect to the applied disturbance

Fig. 14 Voltage and frequency responses during disturbance as per test case- $\mathrm{T}_{2}$

As noted in Table 11, the $d v / d t$ obtained with the conventional method violated the standard limit of $\pm 3 \mathrm{~V} /$ $\mathrm{sec}$, which can damage the sensitive electric/electronic devices connected to the system. Similarly, in the 3-phase voltage profile given in Fig. 15a, b, a reactive load disturbance resulted in $4.92 \%$ of over-voltage and $9.05 \%$ of under-voltage with the conventional method, which got noticeably reduced to $1.19 \%$ and $1.75 \%$, respectively, with the proposed method. Control of over/ under voltages is very vital as these can transform to high impact swell/sags. Also, from Fig. 16c, d, it is noticed that the conventional method leads to a huge variation in voltage profile for a nonlinear load variation, while, the proposed method improved the voltage profile and exhibits smooth response. The voltage deviations further lead to harmonic distortion, which is measured as THD [3]. From Figs. $15 \mathrm{c}$ and $16 \mathrm{e}$, it is noticed that the proposed method exhibits low THD value of $0.77 \%$ and $1.21 \%$, and the conventional method exhibits high THD of $3.30 \%$ and $5.37 \%$, respectively, for the reactive and nonlinear load variations. Thus, the conventional method violated the standard limit of $5 \%$ as notified in Table 11. Having lower THD, the proposed method helps in preserving the voltage waveform shape during disturbances, which is a critical requisite for the integration of RESM and utility-grid.

\section{Conclusions}

The fruitful operation of RESMs majorly depends upon the effectiveness of its V/I controllers. It should precisely control such that the system response should recover quickly within allowable tolerances to deliver non-sluggish and safe supply to the sustained load demands in real-time. From the literature, it is observed that even though, there are many controller design methods are available for different applications, their applicability to RESMs is limited as quantified in Sect. 5.1. So, to overcome the demerits of conventional methods and as a new way of controller parameters' design for RESMs application, this paper proposes the MPZC method. The key merits of this method are outlined as follows.

- The proposed method effectively improves the gain margin, which enhances the stabilization capacity of the system when subjected to disturbances.

- The proposed method improves the transient behavior of both voltage and frequency characteristics, as reported in Table 11. This helps to ensure the safety of sensitive loads that are connected to the RESM plant in real-time.

- Improvement of frequency and voltage transient response in the period of key disturbances helps in retaining the supply power quality requisites for the seamless interconnection of RESMs and utility-grid as suggested by IEEE-1547.

Hence, it is concluded that the proposed MPZC method is a better technique to effectively design the $\mathrm{V} / \mathrm{I}$ controller parameters of RESM plants, which helps to improve the RESM performance in all critical conditions significantly. 


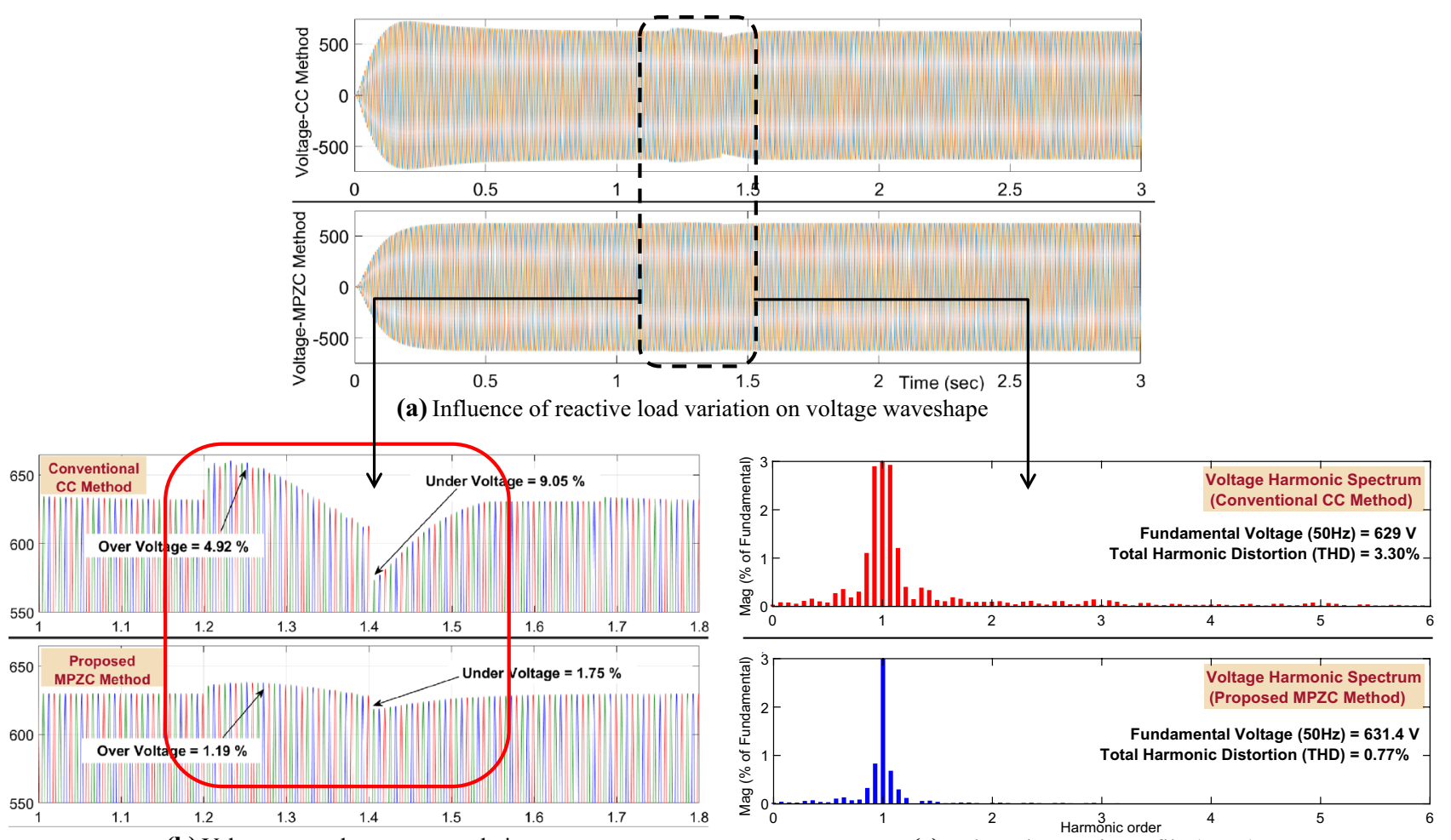

(b) Voltage waveshape - zoomed view

(c) Voltage harmonic profile (THD)

Fig. 15 Impact on 3-Phase voltage profile during disturbance as per test case- $\mathrm{T}_{2}$ 


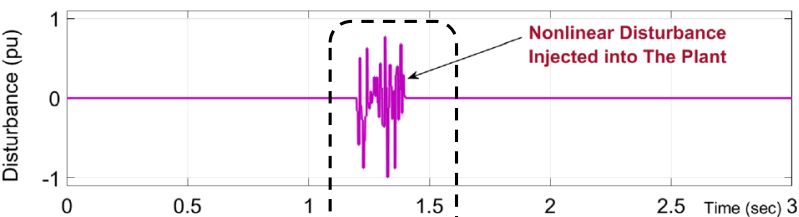

(a) Injected nonlinear 'disturbance

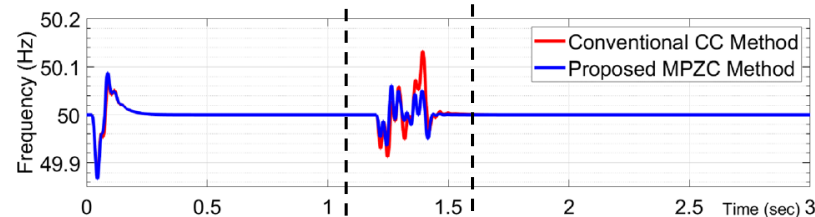

(b) Frequency response for the applied nonlinear disturbance

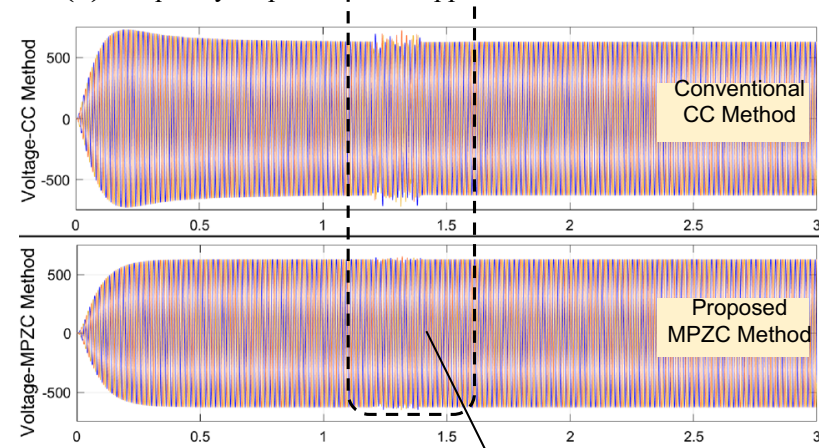

(c) Voltage response for the appliednonlinear disturbance

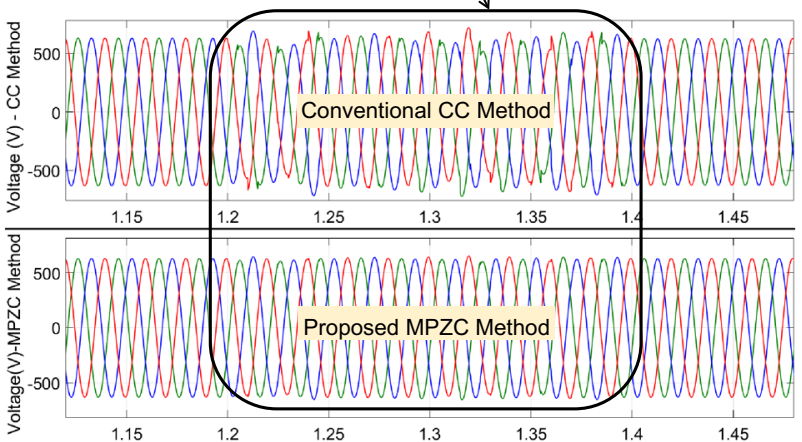

(d) Voltage response for the applied disturbance ${ }^{-}$zoomed view
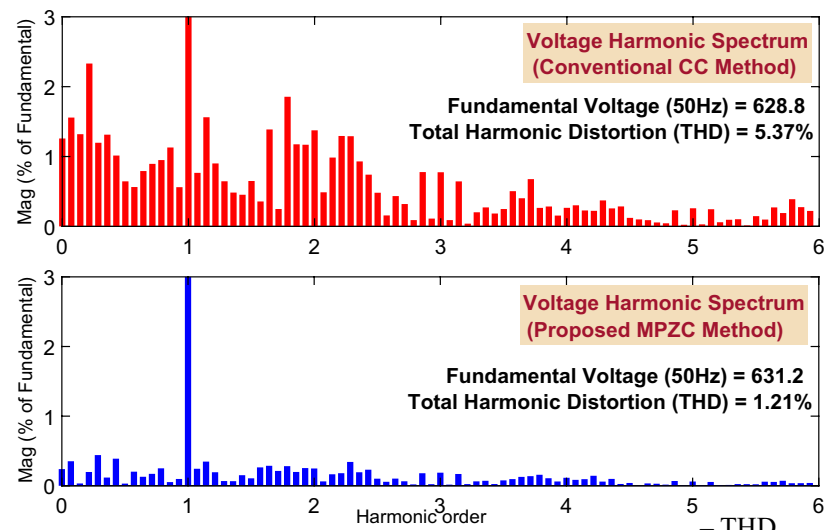

(e) Voltage response for the applied nonlinear disturbance ${ }^{-\mathrm{T}}$

Fig. 16 Frequency and voltage responses for test case- $\mathrm{T}_{3}$
Acknowledgements This work was supported by Project Grant No: SRG/2019/000648, sponsored by the Start-up Research Grant (SRG) scheme of Science and Engineering Research Board (SERB), a statutory body under the Department of Science and Technology (DST), Government of INDIA.

\section{Declarations}

Conflict of interest The authors declare they have no conflict of interest.

Open Access This article is licensed under a Creative Commons Attribution 4.0 International License, which permits use, sharing, adaptation, distribution and reproduction in any medium or format, as long as you give appropriate credit to the original author(s) and the source, provide a link to the Creative Commons licence, and indicate if changes were made. The images or other third party material in this article are included in the article's Creative Commons licence, unless indicated otherwise in a credit line to the material. If material is not included in the article's Creative Commons licence and your intended use is not permitted by statutory regulation or exceeds the permitted use, you will need to obtain permission directly from the copyright holder. To view a copy of this licence, visit http://creativecommons. org/licenses/by/4.0/.

\section{References}

1. Cady ST, Garcia ADD, Hadjicostis CN (2015) A distributed generation control architecture for islanded AC microgrids. IEEE Trans Control Syst Technol 23(5):1717-1735

2. Eid BM, Rahim NA, Selvaraj J, Khateb AHE (2016) Control methods and objectives for electronically coupled distributed energy resources in microgrids: a review. IEEE Syst J 10(2):446-458

3. Kumar YVP, Bhimasingu R (2017) Electrical machines based DC/ $A C$ energy conversion schemes for the improvement of power quality and resiliency in renewable energy microgrids. Int J Electr Power Energy Syst 90:10-26

4. Beltran H, Bilbao E, Belenguer E, Otadui IE, Rodriguez P (2013) Evaluation of storage energy requirements for constant production in PV power plants. IEEE Trans Ind Electron 60(3):1225-1234

5. Xinda K, Lu N, Jin C (2015) Control and size energy storage systems for managing energy imbalance of variable generation resources. IEEE Trans Sustain Energy 6(1):70-78

6. Kerdphol T, Fuji K, Mitani Y, Watanabe M, Qudaih Y (2016) Optimization of a battery energy storage system using particle swarm optimization for stand-alone microgrids. Int J Electr Power Energy Syst 81:32-39

7. Ebrahimi J, Babaei E, Gharehpetian GB (2012) A new multilevel converter topology with reduced number of power electronic components. IEEE Trans Ind Electron 59(2):655-667

8. Kangarlu MF, Babaei E (2013) A generalized cascaded multilevel inverter using series connection of sub multilevel inverters. IEEE Trans Power Electron 28(2):625-636

9. Kumar YVP, Ravikumar B (2016) A simple modular multilevel inverter topology for the power quality improvement in renewable energy based green building microgrids. Electric Power Syst Res J 140:147-161 
10. Mehrasa M, Pouresmaeil E, Mehrjerdi H, Jorgensen BN, Catalao JPS (2015) Control technique for enhancing the stable operation of distributed generation units within a microgrid. Energy Convers Manag 97:362-373

11. Moradi MH, Eskandari M, Hosseinian SM (2016) Cooperative control strategy of energy storage systems and micro sources for stabilizing microgrids in different operation modes. Int J Electr Power Energy Syst 78:390-400

12. Tucci M, Riverso S, Vasquez JC, Guerrero JM, Trecate GF (2016) A decentralized scalable approach to voltage control of DC islanded microgrids. IEEE Trans Control Syst Technol 24(6):1965-1979

13. Ali B, Davoudi A (2012) Hierarchical structure of microgrids control system. IEEE Trans Smart Grid 3(4):1963-1976

14. Li D, Zhu Q, Lin S, Bian XY (2017) A self-adaptive inertia and damping combination control of VSG to support frequency stability. IEEE Trans Energy Convers 32(1):397-398

15. Trivedi A, Singh M (2017) Repetitive controller for vsis in droopbased AC-microgrid. IEEE Trans Power Electron 32(8):6595-6604

16. Ziegler JG, Nichols NB, Rochester NY (1942) Optimum settings for automatic controllers. Trans ASME 64:759-768

17. Murthy BV, Kumar YVP, Kumari UVR (2012) Application of neural networks in process control: automatic/online tuning of PID controller gains for $\pm 10 \%$ disturbance rejection. In: IEEE Int. Conf. on advanced communication control and computing technologies, pp 348-352

18. Wu H, Su W, Liu Z (2014) PID controllers: design and tuning methods. In: 9th Conf. on industrial electronics \& applications, pp 808-813

19. Shamsuzzoha M (2013) Closed-loop PI/PID controller tuning for stable and integrating process with time delay. Ind Eng Chem Res J 52(36):12973-12992

20. Bazanella AS, Pereira LFA, Parraga A (2017) A new method for PID tuning including plants without ultimate frequency. IEEE Trans Control Syst Technol 25(2):637-644

21. Lee JY, Jin M, Chang PH (2014) Variable PID gain tuning method using backstepping control with time-delay estimation and nonlinear damping. IEEE Trans Ind Electron 61(12):6975-6985

22. Dai A, Zhou X, Liu X (2017) Design and simulation of a genetically optimized fuzzy immune PID controller for a novel grain dryer. IEEE Access 5:14981-14990

23. Awouda AEA, Mamat RB (2010) Refine PID tuning rule using ITAE criteria. In: Computer \& automation engineering, Singapore, vol 5, pp 171-176

24. Mallesham G, Mishra S, Jha AN (2011) Ziegler-Nichols based controller parameters tuning for load frequency control in a microgrid. In: IEEE Int. Conf. on energy, automation, and signal, Bhubaneswar, India.

25. Grybos P, Szczygiel R (2008) Pole-Zero cancellation circuit with pulse pile-up tracking system for low noise charge-sensitive amplifiers. IEEE Trans Nucl Sci 55(1):583-590

26. Chen BS, Hsu YY (2008) A minimal harmonic controller for a STATCOM. IEEE Trans Ind Electron 55(2):655-664

27. Tan MT, Chan PK, Lam CK, Ng CW (2010) AC-Boosting frequency compensation with double pole-zero cancellation for multistage amplifiers. Circuits Syst Signal Process 29(5):941-951

28. Huang CY, Wang JJ (2010) A pole/zero cancellation approach to reducing forced vibration in end milling. Int J Mach Tools Manuf 50(7):601-610

29. Mirhaj SA, Shirazi AN, Ashtiani SJ, Shoaei O (2011) High speed sample and hold design using closed-loop pole-zero cancelation. Microelectron J 42(12):1353-1358

30. Seino T, Takahashi I, Ishitsu T, Ueno Y, Kobashi K (2012) An alternative pulse height correction method for pole zero cancellation circuitry. J Nucl Instrum Methods Phys Res Sect A 675:133-138

31. Su JT, Liu CW (2012) Gain scheduling control scheme for improved transient response of DC/DC converters. IET Power Elec 5(6):678-692

32. Ding $C$, Zhang $W$, Jin $D$, Xie $H$, Shen $P$, Chen $L$ (2013) A novel low power UWB cascode SiGe BiCMOS LNA with current reuse and zero-pole cancellation. AEU-Int J Electron Commun 67(4):323-328

33. Bayat FM (2013) Fractional-order unstable pole-zero cancellation in linear systems. J Process Control 23(6):817-825

34. Yepes AG, Vidal A, Malvar J, Lopez O, Gandoy JD (2014) Tuning method aimed at optimized settling time and overshoot for synchronous proportional-integral current control in electric machines. IEEE Trans Power Electron 29(6):3041-3054

35. Golestan S, Monfared M, Freijedo FD, Guerrero JM (2014) Performance improvement of a prefiltered synchronous-referenceframe PLL by using a PID-type loop filter. IEEE Trans Ind Electron 61(7):3469-3479

36. Chopade AS, Khubalkar SW, Junghare AS, Aware MV, Das S (2018) Design and implementation of digital fractional order PID controller using optimal pole-zero approximation method for magnetic levitation system. IEEE/CAA J Automatica Sinica 5(5):977-989

37. Gianluca G, Palumbo G (2019) In-depth analysis of pole-zero compensations in CMOS operational transconductance amplifiers. IEEE Trans Circuits Syst I Regul Papers 66(12):4557-4570

38. Huiliang $C$, Zhang $Y$, Han Z (2019) Pole-zero temperature compensation circuit design and experiment for dual-mass MEMS gyroscope bandwidth expansion. ASME Mechatron 24(2):677-688

39. Jie Y, Shumin F, Yang QC (2020) Compensation strategies based on Bode step concept for actuator rate limit effect on first-order plus time-delay systems. Nonlinear Dyn 99:2851-2866

40. Prasad BS, Jain S, Agarwal V (2008) Universal single-stage gridconnected inverter. IEEE Trans Energy Convers 23(1):128-137

41. Wen T, Liu J, Tongwen C, Marquez HJ (2006) Comparison of some well-known PID tuning formulas. Comput Chem Eng J 30(9):1416-1423

42. Aidan OD (2009) Handbook of PI and PID controller tuning rules, 3rd edn. Imperial College Press

Publisher's Note Springer Nature remains neutral with regard to jurisdictional claims in published maps and institutional affiliations. 